\title{
Physical Exercise-Induced Cardiovascular Adjustments Are Modulated by Muscarinic Cholinoceptors within the Ventromedial Hypothalamic Nucleus
}

\author{
S. P. WANNER ${ }^{1,2}$, J. B. GUIMARÃES ${ }^{1,2}$, W. PIRES ${ }^{1}$, R. B. LA GUARDIA ${ }^{1}$, \\ A. S. HAIBARA ${ }^{2}$, U. MARUBAYASHI ${ }^{2}$, C. C. COIMBRA ${ }^{2}$, N. R. V. LIMA ${ }^{1}$
}

${ }^{1}$ Exercise Physiology Laboratory, School of Physical Education, Physiotherapy and Occupational Therapy, Federal University of Minas Gerais, Belo Horizonte, Minas Gerais, Brazil, ${ }^{2}$ Department of Physiology and Biophysics, Institute of Biological Sciences, Federal University of Minas Gerais, Belo Horizonte, Minas Gerais, Brazil

Received July 16, 2008

Accepted February 16, 2009

On-line June 19, 2009

\section{Summary}

The effects of blocking ventromedial hypothalamic nucleus (VMH) muscarinic cholinoceptors on cardiovascular responses were investigated in running rats. Animals were anesthetized with pentobarbital sodium and fitted with bilateral cannulae into the VMH. After recovering from surgery, the rats were familiarized to running on a treadmill. The animals then had a polyethylene catheter implanted into the left carotid artery to measure blood pressure. Tail skin temperature $\left(T_{\text {tail }}\right)$, heart rate, and systolic, diastolic and mean arterial pressure were measured after bilateral injections of $0.2 \mu \mathrm{l}$ of $5 \times 10^{-9} \mathrm{~mol}$ methylatropine or $0.15 \mathrm{M} \mathrm{NaCl}$ solution into the hypothalamus. Cholinergic blockade of the $\mathrm{VMH}$ reduced time to fatigue by $31 \%$ and modified the temporal profile of cardiovascular and $T_{\text {tail }}$ adjustments without altering their maximal responses. Mean arterial pressure peak was achieved earlier in methylatropine-treated rats, which also showed a 2-min delay in induction of tail skin vasodilation, suggesting a higher sympathetic tonus to peripheral vessels. In conclusion, muscarinic cholinoceptors within the $\mathrm{VMH}$ are involved in a neuronal pathway that controls exercise-induced cardiovascular adjustments. Furthermore, blocking of cholinergic transmission increases sympathetic outflow during the initial minutes of exercise, and this higher sympathetic activity may be responsible for the decreased performance.

\section{Key words}

Acetylcholine • Fatigue $\bullet$ Hypothalamus • Methylatropine

\section{Corresponding author}

N. R. V. Lima, Exercise Physiology Laboratory, Department of Physical Education, School of Physical Education, Physiotherapy and Occupational Therapy, Federal University of Minas Gerais, Av. Antônio Carlos, 6627, 31270-901, Belo Horizonte, Minas Gerais, Brazil. Fax: + 5531 3409-2325. E-mail: nilo@ufmg.br

\section{Introduction}

Exercise-induced increase in metabolic rate requires a higher blood flow in working muscles and cutaneous vessels to match metabolic demands and dissipate the heat produced. Thus, exercise promotes the redistribution of the blood flow among body tissues and resets the baroreflex, simultaneously raising mean arterial pressure and heart rate. These integrated cardiovascular adjustments provide adequate blood perfusion to all body tissues, thereby allowing animals to maintain physical activity. This cardiovascular control depends on both neural signals originating from the brain (central command) and feedback signals arising from the skeletal muscle, aorta and carotid arteries (Williamson et al. 2006).

Previous studies have shown that acetylcholine is involved in the central cardiovascular regulation and that the administration of cholinergic agonists in the brain raises mean arterial pressure in resting rats (Iitake et al. 
1986, Valladão et al. 1990). Moreover, increased cholinergic transmission by intracerebroventricular physostigmine injection leads to higher pressor responses during exercise, suggesting that acetylcholine also modulates blood pressure when the organism is above its resting metabolic rate (Pires et al. 2007). However, no experiments have been performed using central injections of the non-selective muscarinic antagonist methylatropine, a step that is necessary to confirm that the cholinergic pathway is activated during exercise to control blood pressure.

It is also of interest to map the cholinergic neuronal pathways that control blood pressure; the involvement of the medial hypothalamus in cardiovascular regulation has already been reported (Valladão et al. 1990, Takenaka et al. 1996, Marsh et al. 2003, da Silva et al. 2003). Within the medial hypothalamic structures, the ventromedial nucleus $(\mathrm{VMH})$ is a candidate for participating in this circuitry because it has efferent projections to many structures in the forebrain and brain stem that are involved in the central cardiovascular control mechanisms (Luiten and Room 1980, Canteras et al. 1994). This involvement is also supported by the results of an autoradiographic study that identified the existence of muscarinic receptors for acetylcholine in the $\mathrm{VMH}$, particularly the $\mathrm{M}_{3}$ subtype (Kow et al. 1995).

The VMH has been shown to modulate the sympathetic outflow to the periphery, including efferents to the adrenal glands, kidneys and smooth musculature of tail vessels (Morimoto et al. 1986, Yoshimatsu et al. 1987, Smith et al. 1998, Marsh et al. 2003). Additionally, bilateral VMH lesions impair the pressor responses elicited by stimulation of the anteroventral third ventricle (AV3V) (Bastos et al. 1997, do Vale et al. 1997), and functional studies support the participation of acetylcholine-receptive neurons of the VMH in liver glucose mobilization, a marker of sympathetic stimulation (Takahashi et al. 1998).

It is important to point out that the interaction between cardiovascular and thermoregulatory systems determines the cutaneous blood flow (O'Leary and Johnson 1989, Pires et al. 2007) and that tail skin vasodilation is the primary mechanism of heat loss in exercising rats (Wilson et al. 1978, Shellock and Rubin 1984). In previous experiments, we showed that methylatropine injection into the VMH delayed the activation of heat loss mechanisms, leading to a greater heat storage rate and a decreased exercise time to fatigue
(Wanner et al. 2007). These results suggest that a delay in tail skin vasodilation may be related to an impaired sympathetic withdrawal on cutaneous vessels, resulting in a higher sympathetic vasoconstrictor tone and peripheral resistance.

Therefore, the purpose of the present study was to investigate the role of VMH muscarinic cholinoceptors in cardiovascular adjustments in running rats. We also investigated if the decreased exercise time to fatigue induced by blocking VMH cholinoceptors was related to changes in cardiovascular control.

\section{Methods}

Animals

Adult male Wistar rats weighing 250-350 g were used in all experiments. Animals were housed in individual cages under controlled light (0500-1900 hours) and temperature $\left(24.5 \pm 1.6^{\circ} \mathrm{C}\right)$ conditions, with water and rat chow provided ad libitum. All experimental procedures were approved by the Ethics Committee of the Federal University of Minas Gerais for the Care and Use of Laboratory Animals (protocol 017/05) and were carried out in accordance with the regulations described in the Committee's Guiding Principles Manual.

\section{Implantation of brain cannulae}

Under anesthesia with pentobarbital sodium ( $50 \mathrm{mg} / \mathrm{kg}$ body weight i.p.), the animals were fixed to a stereotaxic apparatus, an incision was made in the skin covering the skull at the midline, and a $5 \times 5 \mathrm{~mm}$ craniotomy was performed using a high-speed dental drill. Sterile stainless steel cannulae $(20.0 \mathrm{~mm}$ in length, $0.3 \mathrm{~mm}$ OD, $0.1 \mathrm{~mm}$ ID) were stereotaxically implanted bilaterally, so that the tip of the cannula was aimed at the dorsal aspect of the VMH according to the coordinates described by Paxinos and Watson (2003). The coordinates used were as follows: AP, $2.5 \mathrm{~mm}$ posterior to bregma; ML, $0.6 \mathrm{~mm}$ lateral to midline; DV, $9.0 \mathrm{~mm}$ below dura mater. Both cannulae were anchored firmly to the skull with screws and fixed with acrylic cement. Sterile stainless steel obturators, $0.07 \mathrm{~mm}$ in diameter and of exactly the same length as the cannulae, were inserted into each cannula to prevent obstruction of the lumen.

Immediately after surgery, the rats received an intramuscular prophylactic dose of antibiotics (pentabiotic $24000 \mathrm{IU} / \mathrm{kg}$ body wt) and a subcutaneous injection of analgesic medication (flunixin meglumine, $1.1 \mathrm{mg} / \mathrm{kg}$ body wt). All animals were allowed to recover 
for at least one week before the experiments.

The rats were gradually encouraged to exercise on a treadmill for small animals (Modular Treadmill, Columbus Instruments, OH, USA) by mild electrical stimulation $(0.5 \mathrm{~mA} ; 0.5 \mathrm{mV})$. The familiarization protocol consisted of running at a constant speed of $18 \mathrm{~m} \cdot \mathrm{min}^{-1}$ and $5 \%$ inclination across $5 \mathrm{~min}$ for five consecutive days prior to the experiments (Lima et al. 1998, Wanner et al. 2007). The purpose of these familiarization exercise sessions was to show the animals in which direction to run without becoming entangled in the tail-skin probe thermocouple wires (Lacerda et al. 2005, Prímola-Gomes et al. 2007), allowing a steady performance on the treadmill.

\section{Arterial cannulation}

Following the last familiarization exercise session, the rats were implanted with a catheter to measure pulsatile arterial pressure. Under pentobarbital sodium anesthesia, a catheter (PE-10 connected to a PE-50, Becton Dickinson, Franklin Lakes, NJ, USA) filled with heparin in normal saline was inserted into the left common carotid artery. The free end of the PE-50 polyethylene tubing was tunneled subcutaneously and exteriorized at the cervical dorsal area.

After surgery, the animals received antibiotics and analgesic medication using the same doses and routes of administration as described above. The rats were given two days to recover from this surgery (Pires et al. 2007).

\section{Exercise}

Exercise was performed on a motor-driven treadmill, and its intensity $\left(24 \mathrm{~m} \cdot \mathrm{min}^{-1}\right.$ with a $5 \%$ inclination) corresponded to an oxygen uptake of $\sim 80 \%$ of $\mathrm{VO}_{2 \max }$ (Sonne and Galbo 1980). Fatigue was defined as the point at which the animals were no longer able to keep pace with the treadmill for at least $10 \mathrm{~s}$, even when being stimulated by mild electrical shock (Lima et al. 1998, Wanner et al. 2007). Time to fatigue (min) and workload (kgm) were considered the indexes of exercise performance.

\section{Experimental protocol}

On the day of the experiments, the arterial catheter was connected through a $30 \mathrm{~cm}$ length of PE-50 to a pressure transducer (Biopac Systems, Santa Barbara, CA, USA), coupled to an A/D Data Acquisition System (MP100, Biopac Systems). The animals were allowed to rest in their home cages for $60 \mathrm{~min}$.
After the resting period, a $1 \mu \mathrm{l}$ syringe (Hamilton, Reno, NV, USA) was connected by PE-10 tubing to the brain cannulae to inject the drugs. Rats were randomly assigned to two treatment trials, receiving bilateral injections of either $0.2 \mu \mathrm{l}$ of $0.15 \mathrm{M} \mathrm{NaCl}$ solution (Sal) or $5 \times 10^{-9} \mathrm{~mol}$ methylatropine (Matr; Sigma Chemical, St. Louis, MO, USA). This dose was selected on the basis of previous experiments, which showed that intra-ventromedial injection of $5 \times 10^{-9} \mathrm{~mol}$ of methylatropine solution reduced time to fatigue by $37 \%$ (Wanner et al. 2007). A thermocouple (series 409-B, Yellow Springs Instruments, Dayton, OH, USA) was taped to the tail, and the rats were then placed inside the treadmill. Ten minutes after Matr or Sal injections, the animals were submitted to exercise until fatigue.

Both experimental conditions were carried out at the same time of day with an interval of at least two days between exercise trials. The order of the trials was randomized, and care was taken to ensure that the experimenter who determined the point of fatigue remained blind to the solution injected during each experimental trial throughout the investigation. Ambient temperature in the experimental room was maintained at $23 \pm 1{ }^{\circ} \mathrm{C}$ with relative humidity at $67 \pm 8 \%$.

\section{Measurements and calculations}

Tail skin temperature $\left(\mathrm{T}_{\text {tail }}\right)$ was taken as an index of cutaneous vasodilation (Yanagiya et al. 1999) and was measured using a thermocouple that was taped to the lateral surface of the skin, $\sim 20 \mathrm{~mm}$ from the base of the tail. Mean arterial pressure (MAP), systolic arterial pressure (SAP), diastolic arterial pressure (DAP), and heart rate $(\mathrm{HR})$ measurements were taken from pulsatile arterial pressure recordings with AcqKnowledge 3.7.0 (Biopac Systems). Workload (W), a performance index that takes the differences in body weight into account, was calculated as $\mathrm{W}=[$ body weight $(\mathrm{kg})] \cdot$ [time to fatigue] · [treadmill speed $\left.\left(\mathrm{m} \cdot \mathrm{min}^{-1}\right)\right] \cdot[\sin \theta($ treadmill inclination)] (Lima et al. 2001).

\section{Verification of the position of brain cannulae}

At the end of experiments, rats were deeply anesthetized with pentobarbital sodium $(75 \mathrm{mg} / \mathrm{kg}$ body weight i.p.) and perfused with $0.9 \% \mathrm{NaCl}$ followed by $10 \%$ formalin solution. The brain was removed and stored in formalin solution. After a few days, the brain tissues were frozen at $-13{ }^{\circ} \mathrm{C}$ and cut into $50 \mu \mathrm{m}$ slices using a cryostat microtome (Microm, Riverstone, NSW, USA). Brain slices were stained with a solution of cresyl 

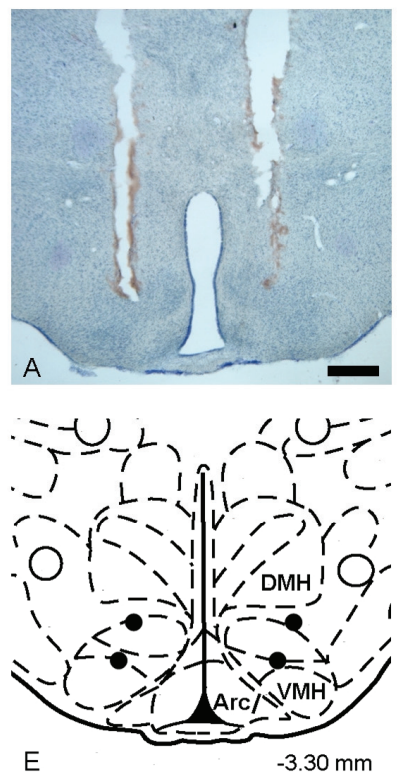
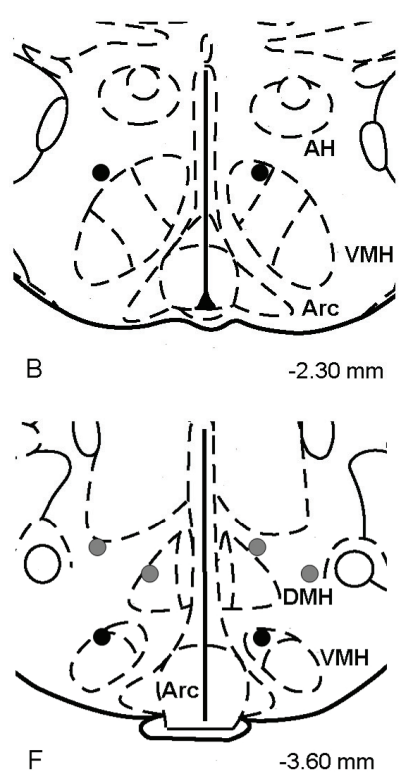
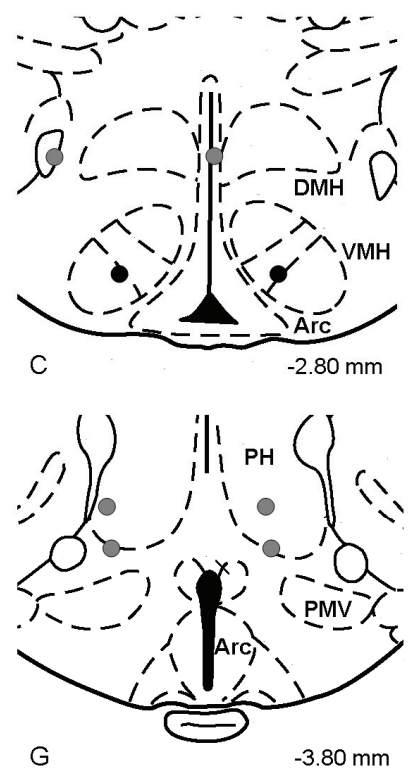

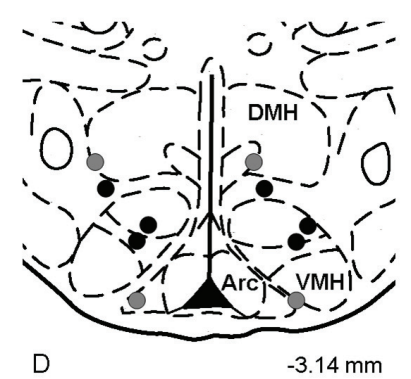

Abbreviations:

$\mathrm{AH}$ - anterior hypothalamic area Arc - arcuate hypothalamic nucleus $\mathrm{DMH}$ - dorsomedial hypothalamic nucleus

$\mathrm{PH}$ - posterior hypothalamic area PMV - ventral premammillary nucleus VMH - ventromedial hypothalamic nucleus

Fig. 1. Photomicrograph of a cresyl violet-stained coronal section from an animal that was inserted with bilateral cannulae in the VMH (A). The horizontal bar's length corresponds to $500 \mu \mathrm{m}$. Schematic representation showing the location of cannulae tips (B-G). Injection sites were localized in the ventromedial hypothalamic nucleus (VMH; black circles) and the peri-VMH region (gray circles).

violet and examined under a light microscope. The positions of the cannulae in the brain were confirmed by comparing them to the description in the Paxinos and Watson's atlas (2003).

\section{Statistical analysis}

Data are expressed as means \pm S.E.M. Time to fatigue, workload performed and time elapsed until MAP peak were compared between treatments using paired or unpaired Student's t-test, as applicable. Differences in cardiovascular adjustments were compared across treatments and time points by two-way analysis of variance (ANOVA), with repeated measures when appropriate. The post hoc Student-Newman-Keuls test was used for multiple comparisons. The correlation between time to fatigue and the time elapsed until MAP peak was assessed using Pearson's correlation coefficient. The significance level was set at $\mathrm{P}<0.05$.

\section{Results}

\section{Brain cannulae placement}

As shown in Figure 1, chronic cannulae were placed bilaterally into the $\mathrm{VMH}$ in eight rats. The cannulae were localized either in the dorsomedial or ventrolateral portion of the nuclei, with an anteriorposterior coordinate ranging from -2.3 to $-3.6 \mathrm{~mm}$.

In seven other rats, we failed to achieve the desired nuclei, and cannulae were localized at the third ventricle, in the posterior hypothalamus or unilaterally in the dorsomedial hypothalamic nucleus. These animals were then used as a control group (i.e. peri-VMH) with the objective of verifying whether methylatropine effects were specific to the VMH.

We failed to obtain blood pressure recordings in two animals treated with methylatropine; for this reason, the number of animals ( $n$ ) is different in Figures 3-5. However, these rats were still submitted to the exercise protocol, and the other parameters (time to fatigue and $\mathrm{T}_{\text {tail }}$ ) were recorded as usual.

\section{Exercise performance}

As expected, muscarinic blockade of the VMH reduced running time to fatigue by $31 \%(15.1 \pm 1.2 \mathrm{~min}$ Matr vs. 21.7 $\pm 1.7 \mathrm{~min} \mathrm{Sal} ; \mathrm{p}<0.01)$. Workload, another index of exercise performance, was also decreased by intra-ventromedial injections of methylatropine $(8.1 \pm 0.6$ kgm Matr vs. 11.8 \pm 1.1 kgm Sal; $\mathrm{p}<0.01$ ).

\section{Tail skin temperature}

Physical exercise induced tail skin vasodilation after a short latency period in both experimental trials (Fig. 2). In control rats, $T_{\text {tail }}$ reached its nadir within 0.5 min after exercise had started, increased at the $4^{\text {th }}$ min $\left(24.91 \pm 0.38{ }^{\circ} \mathrm{C}\right.$ at $4 \mathrm{~min}$ vs. $24.32 \pm 0.19^{\circ} \mathrm{C}$ at $0 \mathrm{~min}$; $\mathrm{p}<0.05$ ), and then remained elevated until the fatigue point. 


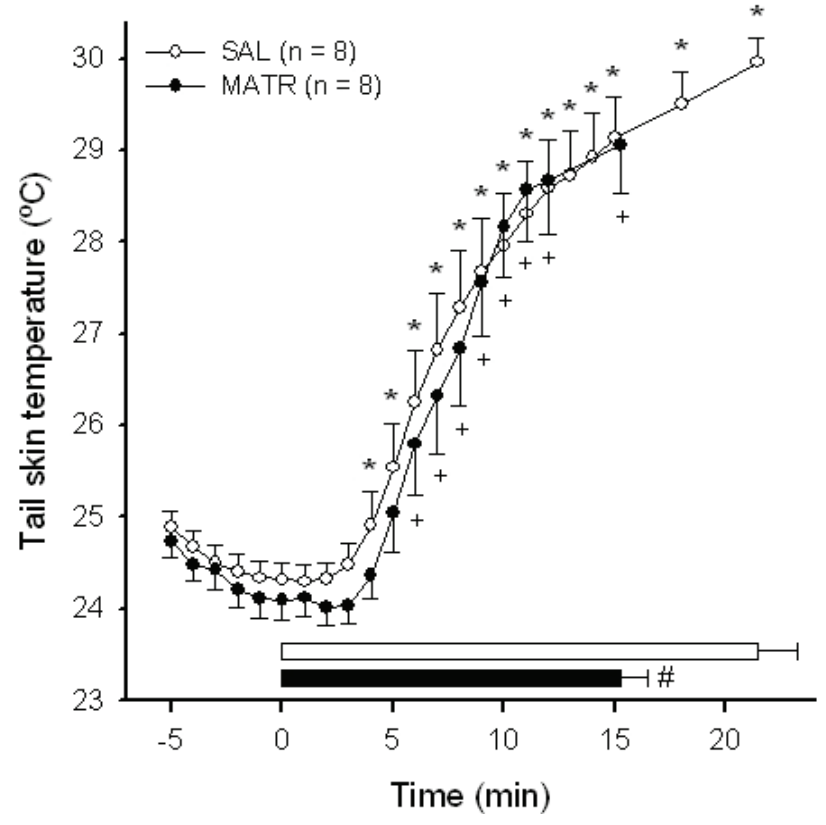

Fig. 2. Temporal profiles of exercise-induced changes in tail skin temperature $\left(T_{\text {tail }}\right)$ after intraventromedial injection of either methylatropine (Matr; $5 \times 10^{-9} \mathrm{~mol}$ ) or $0.15 \mathrm{M} \mathrm{NaCl}$ (Sal). Values are means \pm S.E.M. Time to fatigue is indicated by the horizontal bars at bottom. * $\mathrm{p}<0.05$ compared with corresponding basal values $(0 \mathrm{~min})$ in Sal trial; $+\mathrm{p}<0.05$ compared with corresponding basal values $(0 \mathrm{~min})$ in Matr trial; \# $p<0.05$ compared with Sal trial.

However, in methylatropine-treated rats, $\mathrm{T}_{\text {tail }}$ reached its nadir within $2.5 \mathrm{~min}$ and increased only after $6 \mathrm{~min}$ of exercise $\left(25.80 \pm 0.56{ }^{\circ} \mathrm{C}\right.$ at $6 \mathrm{~min}$ vs. $24.10 \pm$ $0.21{ }^{\circ} \mathrm{C}$ at $\left.0 \mathrm{~min} ; \mathrm{p}<0.05\right)$, therefore, muscarinic blockade of the VMH delayed the exercise-induced increase in $\mathrm{T}_{\text {tail }}$ by $2 \mathrm{~min}$. Methylatropine injections also decreased the mean value of $\mathrm{T}_{\text {tail }}$ during the initial $5 \mathrm{~min}$ of exercise (24.26 $\pm 0.08{ }^{\circ} \mathrm{C}$ Matr vs. 24.64 $\pm 0.10{ }^{\circ} \mathrm{C}$ Sal; $\left.\mathrm{p}<0.01\right)$. At the fatigue point, no differences were observed between the two groups $\left(29.06 \pm 0.53{ }^{\circ} \mathrm{C}\right.$ Matr vs. $\left.29.96 \pm 0.27^{\circ} \mathrm{C} \mathrm{Sal}\right)$.

\section{Cardiovascular adjustments}

As shown in Figure 3A, a slight increase of about $5 \mathrm{mmHg}$ in MAP was observed after the microinjection procedure in both experimental trials (injections were performed $10 \mathrm{~min}$ before the animals were submitted to exercise). There were no differences between treatments at the onset of exercise, indicating that methylatropine had no effects during this period.

Exercise induced an additional increase in MAP that was observed in control rats within $1 \mathrm{~min}$ (118 $\pm 4 \mathrm{~mm} \mathrm{Hg} 1 \mathrm{~min}$ vs. $109 \pm 4 \mathrm{~mm} \mathrm{Hg} 0 \mathrm{~min} ; \mathrm{p}<0.05)$; MAP then remained elevated until fatigue. In rats treated with methylatropine, treadmill running also increased MAP as soon as the exercise started $(125 \pm 4 \mathrm{~mm} \mathrm{Hg}$ 1 min vs. $113 \pm 5 \mathrm{~mm} \mathrm{Hg} 0 \mathrm{~min}$; $<<0.05)$. Methylatropine injections also increased the mean MAP value during the initial $5 \mathrm{~min}$ of exercise $(129 \pm 2 \mathrm{~mm} \mathrm{Hg}$ Matr vs. $123 \pm 2 \mathrm{~mm} \mathrm{Hg} \mathrm{Sal;} \mathrm{p}<0.05)$. No differences in MAP between treatments were observed at the fatigue point (122 $\pm 5 \mathrm{~mm} \mathrm{Hg}$ Matr vs. $122 \pm 5 \mathrm{~mm} \mathrm{Hg} \mathrm{Sal).} \mathrm{The}$ physical exercise-induced alterations observed in SAP (Fig. 3B) were similar to those in MAP.

However, when the time elapsed from the beginning of exercise until MAP peak was evaluated, we observed that it was shorter in rats treated with methylatropine than in controls $(2.7 \pm 0.3 \mathrm{~min}$ Matr vs. $5.6 \pm 1.1 \mathrm{~min}$ Sal; $\mathrm{p}<0.05$ ) (Fig. 4A). Furthermore, MAP was adjusted as a function of time to fatigue percentage; it peaked at $20 \%$ of time to fatigue and then remained elevated until the end of exercise, irrespective of the treatment (Fig. 4B). We also observed a significant positive correlation between the time elapsed until MAP peak and the time to fatigue $(r=0.540 ; p<0.05$; Fig.5).

As illustrated in Figure $3 \mathrm{C}$, physical exercise induced a transitory increase in DAP in control rats which was observed from the $3^{\text {rd }}$ min until the $5^{\text {th }}$ min of treadmill running $(106 \pm 4 \mathrm{~mm} \mathrm{Hg} 5 \mathrm{~min}$ vs. $95 \pm 6 \mathrm{~mm} \mathrm{Hg}$ 0 min; $\mathrm{p}<0.05$ ). On the other hand, muscarinic blockade of $\mathrm{VMH}$ induced faster and more prolonged DAP increases compared to control animals. DAP rose as soon as the exercise started $(106 \pm 4 \mathrm{~mm} \mathrm{Hg} 1 \mathrm{~min}$ vs. $94 \pm 5 \mathrm{~mm}$ $\mathrm{Hg} 0 \mathrm{~min} ; \mathrm{p}<0.05)$ and remained elevated until fatigue. Methylatropine injections also increased the mean value of DAP during the initial $5 \mathrm{~min}$ of exercise $(112 \pm 2 \mathrm{~mm}$ Hg Matr vs. 106 \pm 2 mm Hg Sal; $\mathrm{p}<0.05$ ).

Pre-exercise manipulation of the rats increased HR (426 \pm 10 bpm 0 min vs. $360 \pm 10$ bpm -10 min; $\mathrm{p}<0.001$; grouped data), and there were no differences between treatments at the onset of exercise. Running on the treadmill induced an additional increase in HR within $1 \mathrm{~min}$ of exercise in control rats $(488 \pm 11 \mathrm{bpm} 1 \mathrm{~min}$ vs. $425 \pm 6$ bpm 0 min; $\mathrm{p}<0.05$ ) (Fig. 3D). In rats treated with methylatropine, treadmill running also increased $\mathrm{HR}$ as soon as the exercise started $(495 \pm 8 \mathrm{bpm} 1 \mathrm{~min}$ vs. $428 \pm 10$ bpm 0 min; $\mathrm{p}<0.05)$. HR remained elevated throughout the exercise protocol, and no differences were observed between treatments, including the fatigue point

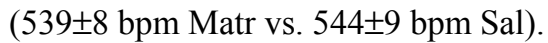

\section{Peri-VMH group}

When the muscarinic receptor blocker was 

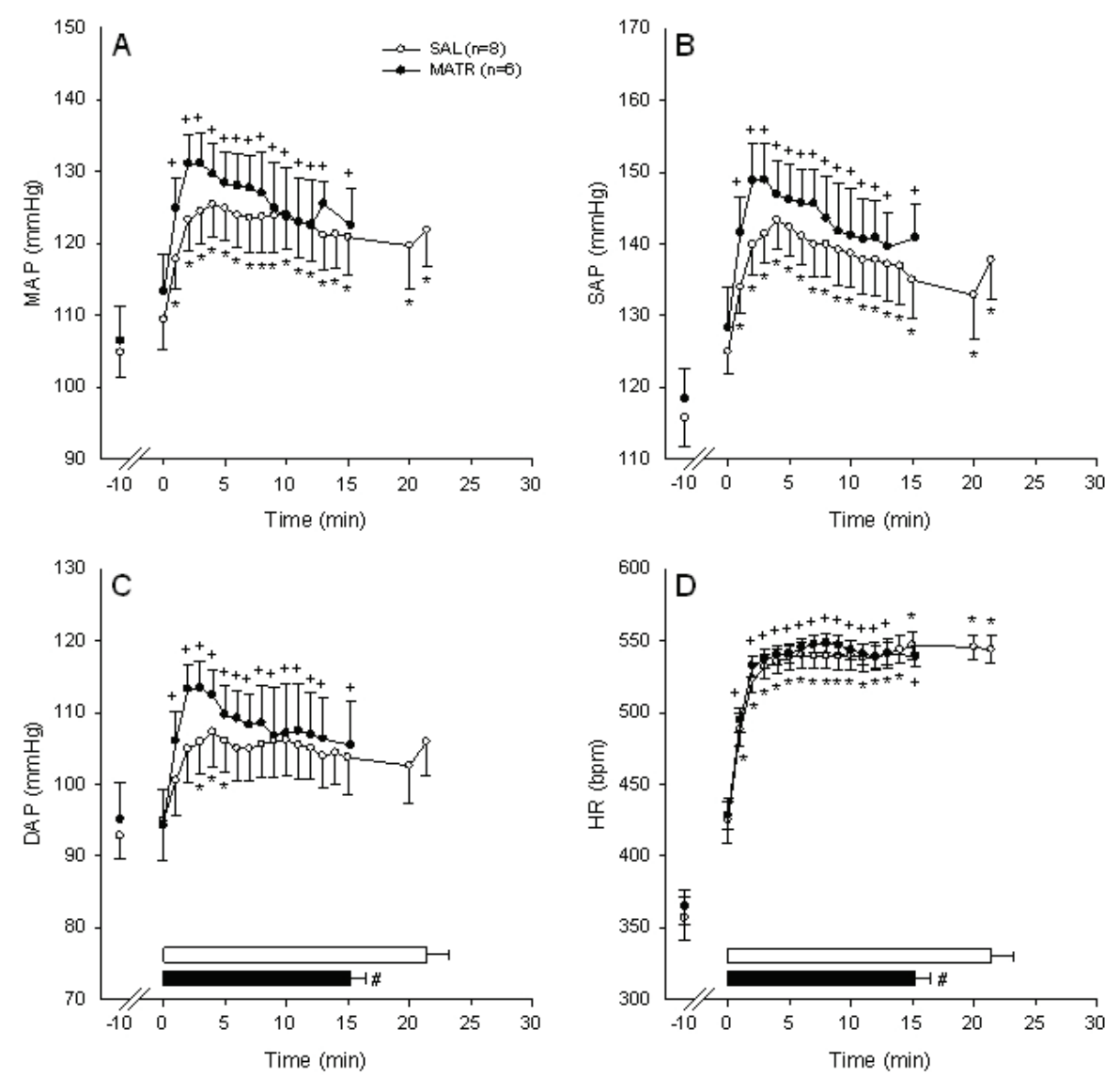

Fig. 3. Temporal profiles of exerciseinduced changes in cardiovascular adjustments after intraventromedial injection of either methylatropine (Matr; $5 \times 10^{-9} \mathrm{~mol}$ ) or $0.15 \mathrm{M} \mathrm{NaCl}$ (Sal). Figure $3 \mathrm{~A}$ presents mean arterial pressure; B: presents systolic arterial pressure; $\mathrm{C}$ : presents diastolic arterial pressure; and $D$ : presents heart rate. Values are means \pm S.E.M. Time to fatigue is indicated by the horizontal bars at bottom. * $\mathrm{p}<0.05$ compared with corresponding basal values $(0 \mathrm{~min})$ in Sal trial; $+p<0.05$ compared with corresponding basal values ( 0 min) in Matr trial; \# $p<0.05$ compared with Sal trial. injected in other hypothalamic areas, no effects were observed in either time to fatigue (17.1 $\pm 1.2 \mathrm{~min}$ Matr vs. $17.4 \pm 1.3 \mathrm{~min}$ Sal) or workload $(9.5 \pm 0.6 \mathrm{kgm}$ Matr vs. $9.6 \pm 0.8 \mathrm{kgm} \mathrm{Sal})$. Furthermore, the blockade of cholinoceptors in the peri-VMH region did not change the exercise-induced increase in $\mathrm{T}_{\text {tail }}$, blood pressure or heart rate. A trend toward a higher MAP during exercise was observed after methylatropine injections into the posterior hypothalamus (139 and $122 \mathrm{~mm} \mathrm{Hg}$ Matr vs. 112 and $115 \mathrm{~mm} \mathrm{Hg} \mathrm{Sal}$; at $5 \mathrm{~min}$ of exercise); however, these data are inconclusive due to the small number of experiments $(n=2)$.

\section{Discussion}

Our present data show that blocking the muscarinic cholinoceptors in the ventromedial hypothalamic nuclei caused that the exercise-induced increase in blood pressure occurred 3 min earlier. This result suggests an augmented sympathetic outflow during the initial minutes of exercise, which was associated with the lower performance of rats treated with methylatropine. The positive correlation observed between the time at which fatigue was reached and the time elapsed until the MAP peak reinforces this point of view. The muscarinic blockade of the VMH also delayed tail skin vasodilation and prolonged the increases in diastolic pressure until fatigue, where this may have induced higher peripheral resistance. However, it is important to point out that this higher methylatropineinduced sympathetic outflow seems to be specific to some peripheral organs, as indicated by the absence of changes in heart rate.

The involvement of the VMH in cardiovascular adjustments has already been described in resting rats using different experimental approaches, including electrolytic and ibotenic acid lesions (Bastos et al. 1997, do Vale et al. 1997), chemical manipulations (Marsh et al. 2003), and neuronal activity recordings (Hirasawa et al. 1996). Furthermore, acetylcholine is one of the neurotransmitters involved in this control, and stimulation of the ventromedial hypothalamus with cholinergic agonists increases blood pressure and heart rate (Valladão et al. 1990, 1992). Adding to the previous evidence showing VMH control of the cardiovascular system, this is the first study to demonstrate that VMH muscarinic cholinoceptors modulate blood pressure during physical exercise. 

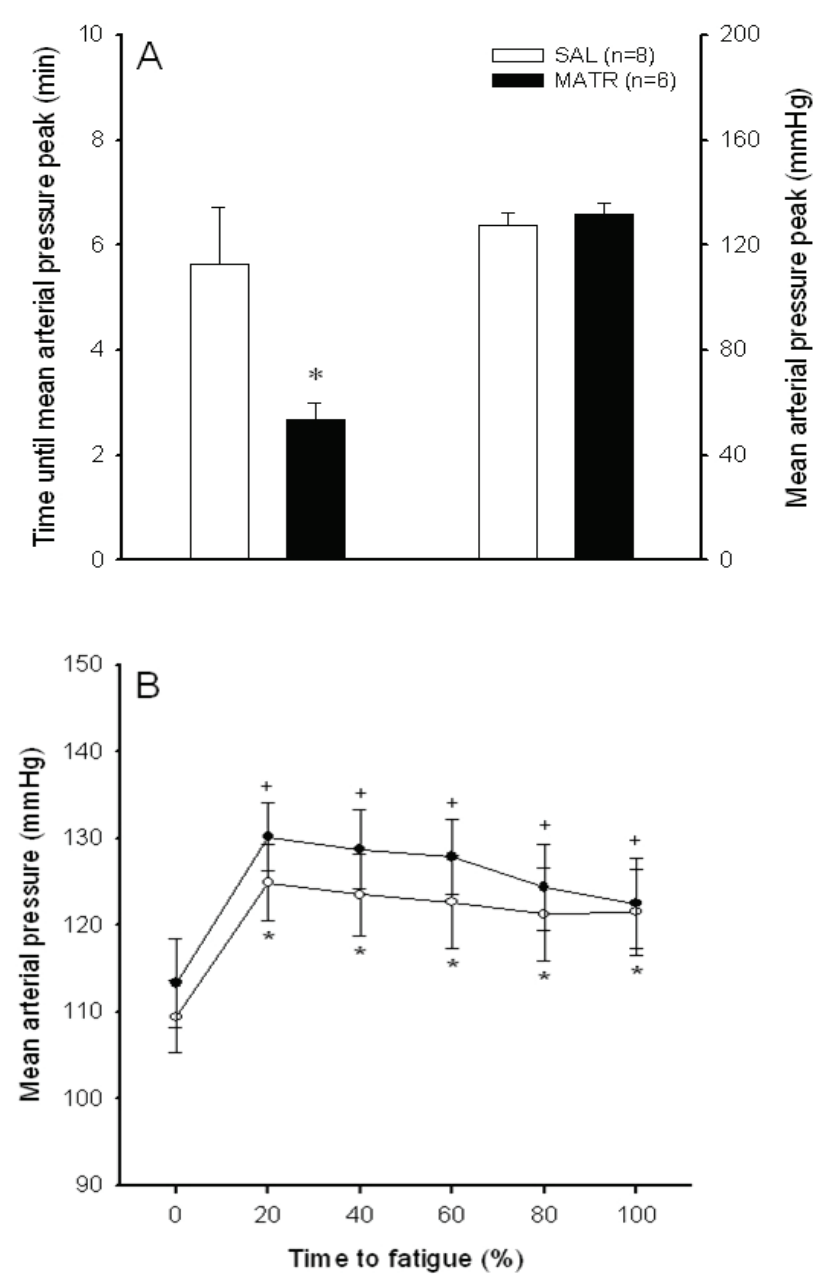

Fig. 4. Effects of bilateral injections of $0.2 \mu \mathrm{l}$ of either Matr $\left(5 \times 10^{-9} \mathrm{~mol}\right)$ or $0.15 \mathrm{M} \mathrm{NaCl}$ into the $\mathrm{VMH}$ on the time elapsed until the peak pressure response during physical exercise (A) and the mean arterial pressure as a function of time to fatigue percentage (B).

There is anatomical and physiological evidence consistent with the hypothesis that acetylcholine within the VMH can regulate the cardiovascular system. Pathways linking the AV3V region to the primary cardiovascular control areas in the medulla are thought to pass through midline structures of the hypothalamus (Knuepfer et al. 1984, Bastos et al. 1997, do Vale et al. 1997). VMH may be one of these relay structures in the hypothalamus because it receives afferents from the medial preoptic area and projects to many nuclei in the forebrain and brain stem with connections to sympathetic preganglionic neurons, such as the dorsomedial and paraventricular hypothalamus, midbrain periaqueductal gray, and the nucleus of the solitary tract in the medulla (Luiten and Room 1980, Canteras et al. 1994).

Sympathetic outflows to individual organs can be differentially affected by central stimulation or autonomic reflexes. The existence of specific neuronal

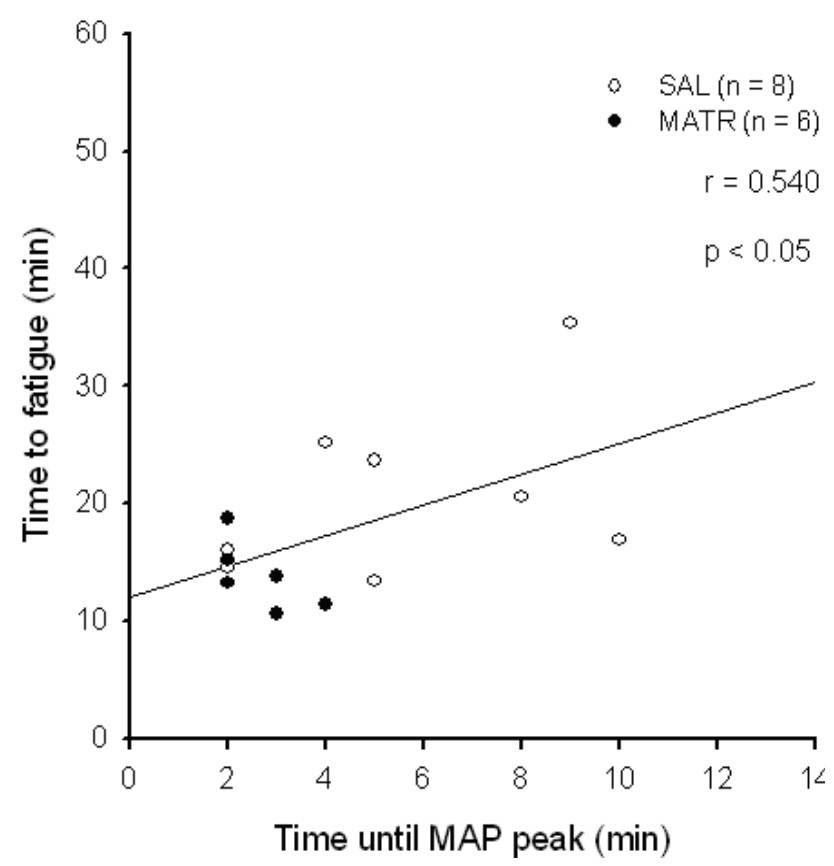

Fig. 5. Correlation between mean arterial pressure peak and time to fatigue in rats treated with $0.2 \mu$ of either $0.15 \mathrm{M} \mathrm{NaCl}$ or Matr $\left(5 \times 10^{-9} \mathrm{~mol}\right)$ into the VMH.

pathways controlling autonomic activity to different organs provides the structural substrate for their differential sympathetic regulation (Morrison 2001). In our experiments, methylatropine injection into the VMH did not modify the exercise-induced increase in heart rate (Fig. 3D), suggesting that the control of sympathetic outflow by the VMH may be site specific, as previously described by Marsh et al. (2003).

It is well known that central cholinergic stimulation increases mean arterial pressure in resting rats and that the administration of atropine, in doses that prevent or attenuate the cholinergic agonists' actions, has no effects on blood pressure (Buccafusco and Brezenoff 1979, Alves et al. 2007). In the present experiments, the methylatropine injections shortened the time to the MAP peak by approximately $3 \mathrm{~min}$ (Fig. 4A). However, the different temporal response in methylatropine-treated rats was not followed by changes in magnitude; the cholinergic blockade did not modify the maximal absolute values of blood pressure. Therefore, the cardiovascular effects induced by VMH muscarinic cholinoceptors stimulation in resting rats and those caused by blockade during exercise are qualitatively different, although this result may seem paradoxical when related to previous reports.

Another relevant point is that physical exercise changes the neural control of the cardiovascular system. The central command arising from the cortical areas and 
the feedback signals arising from different sensors in the periphery, including the contracting muscles, are integrated at the central nervous system (CNS) to directly reset feedforward stimuli to sympathetic and motor systems (Lambert et al. 2005). There is evidence that the VMH may constitute one of these relay areas in the CNS because this hypothalamic nucleus modulates substrate mobilization and hormonal secretion during exercise in a way that is completely opposite to the observed effect in resting rats (Vissing et al. 1989). Therefore, it is reasonable to suggest that exercise may activate an alternative cholinergic pathway that passes through the VMH and that is not tonically activated under resting conditions.

Blood pressure (Fig. 3) and core temperature (Wanner et al. 2007) adjustments seem to be very similar when both treatments - methylatropine and saline - are set as a function of percentage of time to fatigue (Fig. 4B). These observations suggest that acetylcholine in the $\mathrm{VMH}$ may participate in a finely-balanced mechanism that determines the sympathetic outflow for a given performed workload. In this case, the cardiovascular effects promoted by muscarinic blockades may be indirect and evoked by disrupted central afferentefferent integration that overestimates the blood perfusion requirement of active tissues.

The anticipated blood pressure adjustments in running rats treated with methylatropine suggests that the VMH muscarinic cholinoceptors may exert inhibitory effects in a central pathway that stimulates sympathetic outflow during the initial minutes of exercise. The data concerning the control of cutaneous vasomotor tonus are consistent with this hypothesis because the bilateral blockade of VMH muscarinic cholinoceptors led to a delayed exercise-induced increase in skin temperature (Fig. 2). This delay suggests a higher sympathetic outflow to tail vessels because it is accepted that cutaneous vasodilation is mainly a consequence of tail sympathetic activity withdrawal (O'Leary et al. 1985, Yanagiya et al. 1999). Thus, when the organism senses that these responses are not compatible with prolonged and sustained effort, the feeling of fatigue increases and the rats cannot run at the predetermined intensity.

The present data also support previous experiments showing that impaired hypothalamic cholinergic neurotransmission limits exercise performance (Lima et al. 1998, 2001, Wanner et al. 2007). However, we cannot assume that acetylcholine is the only neurotransmitter involved in fatigue development because both the blockade of nitric oxide or angiotensin II neurotransmission (Lacerda et al. 2005, 2006a, 2006b, Leite et al. 2006, 2007) and exacerbating serotoninergic activity (Soares et al. 2003, 2004, 2007) decrease exercise performance by either increasing the heat storage rate or reducing mechanical efficiency. Physical exercise induces simultaneous and different adjustments in many physiological systems, and acute fatigue acts as a protective multifactorial mechanism (Noakes 2000). Therefore, it is likely that this sensation results from an interaction of several neurotransmitters and brain areas (Meeusen et al. 2006) that, together, signal that an effort can no longer be sustained without risks to body homeostasis, thus reducing muscular activation.

There is experimental evidence showing that elevated brain temperatures (Ansley et al. 2009), high heat storage rates (Rodrigues et al. 2003, Marino et al. 2004), reductions in either mechanical efficiency (Soares et al. 2003, Lacerda et al. 2006a, Leite et al. 2007) or muscle glycogen (Rauch et al. 2005), and other factors may signal for effort cessation. We have previously provided insights into this multifactorial characteristic of fatigue, using pharmacological manipulations of cholinergic neurotransmission. Intracerebroventricular physostigmine injection enhanced tail heat loss mechanisms and thus attenuated the exercise-induced increase in core body temperature. Despite the lower core temperature at the fatigue point, central cholinergic stimulation failed to increase exercise performance, suggesting that other physiological systems could be involved in the fatigue sensation under these experimental conditions (Rodrigues et al. 2004, 2008, Pires et al. 2007).

The present data corroborate the finding that the redistribution of blood flow between vascular beds is a limiting factor to prolonged physical effort. A higher sympathetic tone to skin vessels may shift a greater amount of blood from the periphery to central circulation and may contribute to a faster increase in MAP. This may explain the delay in activating the tail heat loss mechanism, which we have previously shown to occur at higher core temperatures in methylatropine-treated rats (Wanner et al. 2007). The delayed cutaneous vasodilation increases the heat storage rate, contributing to the reduced performance of these animals.

In conclusion, muscarinic cholinoceptors within the VMH are involved in neuronal circuitry that modulates exercise-induced blood pressure adjustments and heat loss mechanisms. Furthermore, our data suggest that a VMH muscarinic blockade increases sympathetic 
outflow during the initial phase of exercise; this increase may be related to the reduced performance observed in rats treated with methylatropine.

\section{Conflict of Interest}

There is no conflict of interest.

\section{Acknowledgements}

The authors are indebted to the Coordenadoria de Apoio ao Pessoal de Nível Superior (CAPES), Conselho Nacional de Desenvolvimento Científico e Tecnológico (CNPq), Fundação de Amparo à Pesquisa do Estado de Minas Gerais (FAPEMIG), and Pró-Reitoria de Pesquisa da Universidade Federal de Minas Gerais for financial support. We also acknowledge the technical assistance of André Luis Pimenta de Faria and Maria Aparecida Vasconcelos Faria.

\section{References}

ALVES FHF, CRESTANI CC, RESSTEL LBM, CORRÊA FMA: Cardiovascular effects of carbachol microinjected into the bed nucleus of the stria terminalis of the rat brain. Brain Res 1143: 161-168, 2007.

ANSLEY L, MARVIN G, SHARMA A, KENDALL MJ, JONES DA, BRIDGE MW: The effects of head cooling on endurance and neuroendocrine responses to exercise in warm conditions. Physiol Res 57: 863-872, 2009.

BASTOS R, MENANI JV, SAAD WA, RENZI A, SILVEIRA JEN, CAMARGO LAA: Ventromedial hypothalamus lesions increase the dipsogenic responses and reduce the pressor responses to median preoptic area activation. Physiol Behav 62: 311-316, 1997.

BUCCAFUSCO JJ, BREZENOFF HE: Pharmacological study of a cholinergic mechanism within the rat posterior hypothalamic nucleus which mediates a hypertensive response. Brain Res 165: 295-310, 1979.

CANTERAS NS, SIMERLY RB, SWANSON LW: Organization of projections from the ventromedial nucleus of the hypothalamus: a Phaseolus vulgaris-leucoagglutinin study in the rat. J Comp Neurol 348: 41-79, 1994.

Da SILVA LG, De MENEZES RC, Dos SANTOS RA, CAMPAGNOLE-SANTOS MJ, FONTES MA: Role of periaqueductal gray on the cardiovascular response evoked by disinhibition of the dorsomedial hypothalamus. Brain Res 984: 206-214, 2003.

Do VALE CF, CAMARGO GMP, SAAD WA, MENANI JV, RENZI A, LUIZ AC, CERRI PS, CAMARGO LAA: Effect of ibotenate lesions of the ventromedial hypothalamus on the water and salt intake induced by activation of the median preoptic nucleus in sodium-depleted rats. J Auton Nerv Syst 66: 19-25, 1997.

HIRASAWA M, NISHIHARA M, TAKAHASHI M: Neural activity in the VMH associated with suppression of the circulatory system in rats. Physiol Behav 59: 1017-1023, 1996.

IITAKE K, SHARE L, OUCHI Y, CROFTON JT, BROOKS DP: Central cholinergic control of vasopressin release in conscious rats. Am J Physiol 251: E146-E150, 1986.

KNUEPFER MM, JOHNSON AK, BRODY MJ: Vasomotor projections from the anteroventral third ventricle (AV3V) region. Am J Physiol 247: H139-H145, 1984.

KOW LM, TSAI YF, WEILAND NG, MCEWEN BS, PFAFF DW: In vitro electro-pharmacological and autoradiographic analyses of muscarinic receptor subtypes in rat hypothalamic ventromedial nucleus: implications for cholinergic regulation of lordosis. Brain Res 694: 29-39, 1995.

LACERDA AC, MARUBAYASHI U, COIMBRA CC: Nitric oxide pathway is an important modulator of heat loss in rats during exercise. Brain Res Bull 67: 110-116, 2005.

LACERDA AC, MARUBAYASHI U, BALTHAZAR CH, COIMBRA CC: Evidence that brain nitric oxide inhibition increases metabolic cost of exercise, reducing running performance in rats. Neurosci Lett 393: 260-263, 2006a.

LACERDA AC, MARUBAYASHI U, BALTHAZAR CH, LEITE LH, COIMBRA CC: Central nitric oxide inhibition modifies metabolic adjustments induced by exercise in rats. Neurosci Lett 410: 152-156, 2006b.

LAMBERT EV, ST CLAIR GIBON A, NOAKES TD: Complex systems model of fatigue: integrative homoeostatic control of peripheral physiological systems during exercise in humans. Br J Sports Med 39: 52-62, 2005.

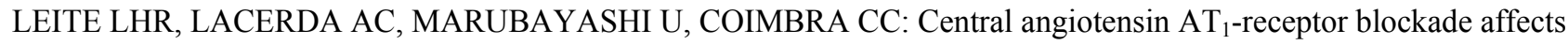
thermoregulation and running performance in rats. Am J Physiol 291: R603-R607, 2006. 


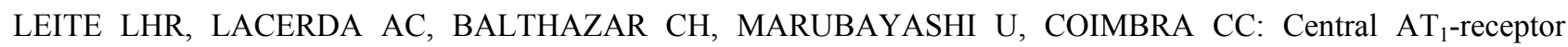
blockade increases metabolic cost during exercise reducing mechanical efficiency and running performance in rats. Neuropeptides 41: 189-194, 2007.

LIMA NRV, COIMBRA CC, MARUBAYASHI U: Effect of intracerebroventricular injection of atropine on metabolic responses during exercise in untrained rats. Physiol Behav 64: 69-74, 1998.

LIMA NRV, PEREIRA W, REIS AM, COIMBRA CC, MARUBAYASHI U: Prolactin release during exercise in normal and adrenodemedullated untrained rats submitted to central cholinergic blockade with atropine. Horm Behav 40: 526-532, 2001.

LUITEN PG, ROOM P: Interrelations between lateral, dorsomedial and ventromedial hypothalamic nuclei in the rat. An HRP study. Brain Res 190: 321-332, 1980.

MARINO FE: Anticipatory regulation and avoidance of catastrophe during exercise-induced hyperthermia. Comp Biochem Physiol B 139: 561-569, 2004.

MARSH AJ, FONTES MAP, KILLINGER S, PAWLAK DB, POLSON JW, DAMPNEY RAL: Cardiovascular responses evoked by leptin acting on neurons in the ventromedial and dorsomedial hypothalamus. Hypertension 42: 488-493, 2003.

MEEUSEN R, WATSON P, HASEGAWA H, ROELANDS B, PIACENTINI MF: Central fatigue: the serotonin hypothesis and beyond. Sports Med 36: 881-909, 2006.

MORIMOTO A, MURAKAMI N, ONO T, WATANABE T, SAKATA Y: Stimulation of ventromedial hypothalamus induces cold defense responses in conscious rabbits. Am J Physiol 250: R560-R566, 1986.

MORRISON SF: Differential control of sympathetic outflow. Am J Physiol 281: R683-R698, 2001.

NOAKES TD: Physiological models to understand exercise fatigue and the adaptations that predict or enhance athletic performance. Scand J Med Sci Sports 10: 123-145, 2000.

O'LEARY DS, JOHNSON JM, TAYLOR WF. Mode of neural control mediating rat tail vasodilation during heating. J Appl Physiol 59: 1533-1538, 1985.

O'LEARY DS, JOHNSON JM: Baroreflex control of the rat tail circulation in normothermia and hyperthermia. $J$ Appl Physiol 66: 1234-1241, 1989.

PAXINOS G, WATSON C: The Rat Brain in Stereotaxic Coordinates: The New Coronal Set. Elsevier Academic Press, San Diego, 2003.

PIRES W, WANNER SP, LA GUARDIA RB, RODRIGUES LOC, SILVEIRA SA, COIMBRA CC, MARUBAYASHI U, LIMA NRV: Intracerebroventricular physostigmine enhances blood pressure and heat loss in running rats. J Physiol Pharmacol 58: 3-17, 2007.

PRÍMOLA-GOMES TN, PIRES W, RODRIGUES LOC, COIMBRA CC, MARUBAYASHI U, LIMA NRV: Activation of the central cholinergic pathway increases post-exercise tail heat loss in rats. Neurosci Lett 413: $1-5,2007$.

RAUCH HG, ST CLAIR GIBSON A, LAMBERT EV, NOAKES TD: A signalling role for muscle glycogen in the regulation of pace during prolonged exercise. Br J Sports Med 39: 34-38, 2005.

RODRIGUES AG, LIMA NRV, COIMBRA CC, MARUBAYASHI U: Evidence that exercise-induced heat storage is dependent on adrenomedullary secretion. Physiol Behav 94: 463-467, 2008.

RODRIGUES AG, LIMA NRV, COIMBRA CC, MARUBAYASHI U: Intracerebroventricular physostigmine facilitates heat loss mechanisms in running rats. $J$ Appl Physiol 97: 333-338, 2004.

RODRIGUES LOC, OLIVEIRA A, LIMA NRV, MACHADO-MOREIRA CA: Heat storage rate and acute fatigue in rats. Braz J Med Biol Res 36: 131-135, 2003.

SHELLOCK FG, RUBIN SA: Temperature regulation during treadmill exercise in the rat. J Appl Physiol 57: 1872$1877,1984$.

SMITH JE, JANSEN AS, GILBEY MP, LOEWY AD: CNS cell groups projecting to sympathetic outflow of tail artery: neural circuits involved in heat loss in the rat. Brain Res 786: 153-164, 1998.

SOARES DD, COIMBRA CC, MARUBAYASHI U: Tryptophan-induced central fatigue in exercising rats is related to serotonin content in preoptic area. Neurosci Lett 415: 274-278, 2007.

SOARES DD, LIMA NRV, COIMBRA CC, MARUBAYASHI U: Evidence that tryptophan reduces mechanical efficiency and running performance in rats. Pharmacol Biochem Behav 74: 357-362, 2003. 
SOARES DD, LIMA NRV, COIMBRA CC, MARUBAYASHI U: Intracerebroventricular tryptophan increases heating and heat storage rate in exercising rats. Pharmacol Biochem Behav 78: 255-261, 2004.

SONNE B, GALBO H: Simultaneous determinations of metabolic and hormonal responses, heart rate, temperature and oxygen uptake in running rats. Acta Physiol Scand 109: 201-209, 1980.

TAKAHASHI A, KISHI E, ISHIMARU H, IKARASHI Y, MARUYAMA Y: Stimulation of rat hypothalamus by microdialysis with $\mathrm{K}^{+}$: increase of ACh release elevates plasma glucose. Am J Physiol 275: R1647-R1653, 1998.

TAKENAKA K, SASAKI S, UCHIDA A, FUJTA H, NAKAMURA K, ICHIDA T, ITOH H, NAKATA T, TAKEDA $\mathrm{K}$, NAKAGAWA $\mathrm{M}$ : $\mathrm{GABA}_{\mathrm{B}}$-ergic stimulation in hypothalamic pressor area induces larger sympathetic and cardiovascular depression in spontaneously hypertensive rats. Am J Hypertens 9: 964-972, 1996.

VALLADÃO AS, SAAD WA, CAMARGO LAA, RENZI A, DE LUCA LA JR, MENANI JV: Interaction between cholinergic and adrenergic pathways of the hypothalamic ventromedial nucleus on cardiovascular regulation. J Auton Nerv Syst 30: 239-246, 1990.

VALLADÃO AS, SAAD WA, CAMARGO LAA, RENZI A, DE LUCA LA JR, MENANI JV: AV3V lesion reduces the pressor, dipsogenic, and natriuretic responses to ventromedial hypothalamus activation. Brain Res Bull 28 : 909-914, 1992.

VISSING J, WALLACE JL, SCHEURINK AJ, GALBO H, STEFFENS AB: Ventromedial hypothalamic regulation of hormonal and metabolic responses to exercise. Am J Physiol 256: R1019-R1026, 1989.

WANNER SP, GUIMARÃES JB, RODRIGUES LOC, MARUBAYASHI U, COIMBRA CC, LIMA NRV: Muscarinic cholinoceptors in the ventromedial hypothalamic nucleus facilitate tail heat loss during physical exercise. Brain Res Bull 73: 28-33, 2007.

WILLIAMSON JW, FADEL PJ, MITCHELL JH: New insights into central cardiovascular control during exercise in humans: a central command update. Exp Physiol 91: 51-58, 2006.

WILSON NC, GISOLFI CV, FARBER J, HINRICHS DK: Colonic and tail skin temperature responses of the rat at selected running speeds. J Appl Physiol 44: 571-575, 1978.

YANAGIYA Y, YOSHIMURA R, HORI M, KUWAHARA M, TSUBONE H, SUGANO S: The influence of chronic sympathectomy on cutaneous blood flow in the rat tail. J Vet Med Sci 61: 795-801, 1999.

YOSHIMATSU H, OOMURA Y, KATAFUCHI T, NIIJIMA A: Effects of hypothalamic stimulation and lesion on adrenal nerve activity. Am J Physiol 253: R418-R424, 1987. 